\title{
Условия формирования әвдиалитовых руд Ловозерского месторождения и критерии поисков редкоземельных руд, циркония и гафния
}

\author{
Когарко Л.Н. \\ Институт геохимии и аналитической химии им. В.И. Вернадского РАН, Москва, kogarko@geokhi.ru
}

Аннотация. Детальные исследования показали, что смена форм выделения эвдиалита (и времени его кристаллизации) представляет собой новый геохимический критерий рудоносности щелочных магм на редкометальное сырье (эвдиалитовые руды). Сформулирован новый принцип рудоносности щелочных магм: необходимым условием формирования рудного месторождения является ранняя насыщенность щелочных магм в отношении рудного минерала. Если концентрация рудного компонента значительно ниже котектической (насыщения), то насыщение расплава и кристаллизация рудного минерала будет осуществляться на поздних стадиях формирования пород в малом объеме интерстициального расплава, когда явления конвективногравитационной дифференциации и сегрегации минеральных фаз в виде рудных залежей затруднены. Это приводит к рассеиванию рудных компонентов в виде ксеноморфных выделений акцессорных минералов.

Породы дифференцированного комплекса (нижняя зона Ловозерского месторождения), породы Хибинского массива, содержащие ксеноморфный эвдиалит, не перспективны на эвдиалитовые руды. Эвдиалитовые месторождения связаны с верхней зоной Ловозерской интрузии, содержащей идиоморфный ранний эвдиалит. Насыщение исходной магмы в отношении эвдиалита происходит после кристаллизации около 80 \% интрузии.

Предложенный критерий применим к крупнейшим щелочным массивам мира. С Илимауссакским массивом (Гренландия), в породах которого кристаллизовался ранний, идиоморфный эвдиалит связано суперкрупное месторождение эвдиалитовых руд, в то время как в Хибинском массиве и щелочном комплексе Пилансберг, породы которых содержат поздний ксеноморфный эвдиалит месторождения этого типа отсутствуют..

Ключевые слова: Ловозёрское редкометальное месторождение, эвдиалитовая руда, формы выделения эвдиалита, насыщенность магмы эвдиалитом.

\section{A New Geochemical Criterion for Rare-Metal Mineralization of High-Alkalic Magmas (Lovozero Deposit, Kola Peninsula)}

\author{
Academician L. N. Kogarko \\ Vernadsky Institute of Geochemistry and Analytical Chemistry,Russian Academy of Sciences, Moscow, \\ kogarko@geokhi.ru
}

\begin{abstract}
Detailed studies have shown that a change in the eudialyte occurrence forms (and the moment of its crystallization) is a new geochemical criterion for rare metal ore content in alkalic magmas (eudialyte ores). A new principle of the presence of ores in alkalic magmas has been formulated: a prerequisite for the formation of an ore deposit is early saturation of alkalic magmas with an ore mineral. If the ore component concentration is significantly lower than the cotectic (saturation), then melt saturation and crystallization of an ore mineral will take place at later stages of rock formation in a small volume of the interstitial melt, when the phenomena of convectivegravity differentiation and segregation of mineral phases in the form of ore deposits are hampered. This leads to dispersion of the ore components in the form of xenomorphic grains of accessory minerals. Rocks of the differentiated complex (lower zone of the Lovozero deposit) and rocks of the Khibiny massif contain xenomorphic eudialyte and are not promising for eudialyte ores. Eudialyte deposits are associated with the upper zone of the Lovozero intrusion where euhedral early eudialyte occurs. The initial magma is saturated with eudialyte after crystallization of about $80 \%$ of the intrusion. The proposed criterion is applicable to the largest alkalic massifs in the world. The Ilimaussaq massif (Greenland), the rocks of which contain early crystallized, euhedral eudialyte, hosts a superlarge eudialyte ore deposit. Unlike the Khibiny massif and the Pilanesberg alkalic complex, the rocks of which contain late xenomorphic eudialyte, this massif has no deposits of this type.
\end{abstract}

Key words: rare metal deposits of Lovozero massif, eudialyte ore, morphology of eudialyte, eudialyte saturation of magma.

Разработка геохимических критериев рудоносности природных магм является одной из важнейших задач современной геохимии. Успешное прогнозирование месторождений требует фунда- 
ментальных работ по установлению физико-химических параметров концентрирования рудного вещества. Поиск, разведка и, в дальнейшем, оценка запасов магматического рудного сырья тесно связаны с выяснением механизмов кумуляции рудных минеральных фаз в магматической камере и необходимых условий для формирования рудоносных тел и горизонтов.

Настоящая работа посвящена выяснению условий, благоприятных для возникновения магматических месторождений кумулятивного типа и разработке критериев рудоносности щелочных магм, с дифференциацией которых связаны крупнейшие месторождения редких земель, циркония, гафния, ниобия, фосфора и других элементов. Потребление и цены на стратегические металлы значительно выросли в последнее десятилетие в связи с заметным расширением технологий, потребляющих эти металлы. В этой связи щелочные формации можно рассматривать как сырье будущего - сырье 21 века.

Самыми продуктивными формациями на стратегические металлы - REE, $\mathrm{Zr}, \mathrm{Hf}, \mathrm{Nb}$, Ta, радиоактивные элементы являются щелочные породы и карбонатиты, которые также относятся к ряду щелочных пород. Особый интерес представляют формации агпаитовых нефелиновых сиенитов, к которым приурочены суперкрупные месторождения эвдиалита, лопарита и апатита (Кольский полуостров, Южная Африка, Бразилия, Гренландия). С гигантской Ловозерской интрузией связаны редкометальные эвдиалитовые руды - ценнейший источник тяжелых редких земель, циркония и гафния. Кроме того, эвдиалитовое месторождение представлено комплексными рудами и содержат также марганец, ниобий, скандий, радиоактивные металлы и др.

Ловозерский щелочной массив, расположенный в центральной части Кольского полуострова, занимает площадь в 650 км $^{2}$ и залегает среди архейских гранитогнейсов. Его возраст $360 \pm 10$ млн. лет (Kramm, Kogarko, 1994). Согласно схеме В.И. Герасимовского и др., (Герасимовский и др., 1966), Ловозерский щелочной массив сформировался в три главные интрузивные фазы.

Нефелиновые и нозеановые сиениты I фазы встречаются в основном в виде ксенолитов. Дифференцированный комплекс (II интрузивная фаза) представляет собой ритмически слоистую мощную (свыше 1500 м) интрузию, сложенную закономерно чередующимися в вертикальном разрезе пластами нефелиновых сиенитов различного состава - уртитами, фойяитами, луявритами, состоящими в основном из нефелина, калиевого полевого шпата и эгирина. Для этих пород в целом характерно увеличение коэффициента агпаитности (средняя величина $\mathrm{K}_{\text {агп }} 1.41$ ) и появление типичных минералов агпаитового парагенезиса: лопарита, виллиомита, содалита, лампрофиллита, рамзаита и др. Комплекс эвдиалитовых луявритов (III фаза) - это пластообразная интрузия мощностью до 450-600 м, прорывающая и перекрывающая породы II фазы. Этот комплекс сложен слаборасслоенной толщей эвдиалитовых луявритов от лейко до меланократовых, причем в породах верхних частей разреза возрастают содержания темноцветных минералов. Эвдиалитовые луявриты отличаются наиболее высоким $\mathrm{K}_{\text {агп }}-1.50$ и максимальным содержанием $\mathrm{ZrO}_{2}-1.36$ мас. \%, а также ярко выраженным агпаитовым парагенезисом минералов, особенно в верхних горизонтах (мурманит-ломоносовит, лампрофиллит, рамзаит, ловозерит). Эвдиалит в этих породах становится главным породообразующим минералом. Рудные горизонты, обогащенные эвдиалитом, распологаются в верхней зоне эвдиалитового комплекса, представленного эвдиалитовыми луявритами. В самой верхней зоне в виде линз и слоев, развиты редкометальные руды - эвдиалититы, состоящие на 85-90 \% из эвдиалита. Таким образом, в верхней зоне эвдиалитовой интрузии содержание эвдиалита значительно возрастает, вследствие этого вся верхняя часть III интрузивной фазы представляет собой руду на редкие земли, цирконий и гафний.

Мы детально исследовали минералогию и геохимию агпаитовых щелочных пород в вертикальном разрезе Ловозерского месторождения, особое внимание было уделено формам выделения и составу эвдиалита. Проведенные работы (до глубин 2200-2300м общего разреза Ловозерского массива) выявили целый ряд особенностей строения и минерального состава этой интрузии. Наиболее интересным является смена минеральных парагенезисов в вертикальном разрезе. В наиболее глубинных, не выходящих на поверхность зонах дифференцированного комплекса Ловозерского месторождения (скважины 904, 905 и др.) набор породообразующих минералов - нефелин, калиевый 
полевой шпат и эгирин не меняется, в то время как высокощелочные агпаитовые акцессорные минералы верхней части разреза - эвдиалит и лампрофиллит - заменяютя менее щелочными, близкими к миаскитовым ассоциациями (сфен, мозандритовая группа минералов и циркон). В этой части разреза эвдиалит отсутствует. На этих глубинах главными минералами-концентраторами циркония являются циркон и ловенит.

При движении вверх по разрезу появляются циркониевые минералы - катаплеит, келдышит и, по нашим предварительным данным, армстронгит. С глубины порядка 2100 м в ассоциации нефелин-калиевый полевой шпат-эгирин появляется эвдиалит в ассоциации с паракелдышитом и минералами ловенитовой группы. Во всем интервале глубин дифференцированного комплекса, начиная с 2100 м, эвдиалит кристаллизуется на позднемагматическом этапе, он образует ксеноморфные выделения, приуроченные к интерстициям породообразующих минералов - нефелина, калиевого полевого шпата, эгирина и амфибола (рис. 1).

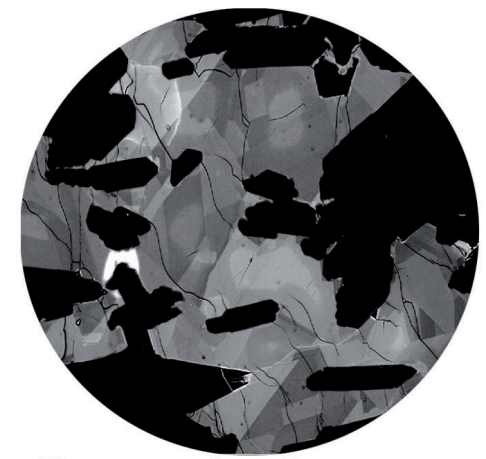

Ксеноморфный эвдиалит в нижней зоне

Ловозерского месторождения (фото в отраженных электронах, х10)

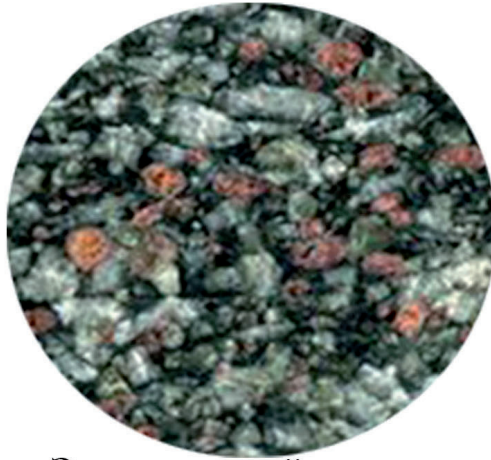

Эвдиалитовый луяврит, содержащий идиоморфный эвдиалит

(фото в проходящем свете, $\mathbf{x} 2)$

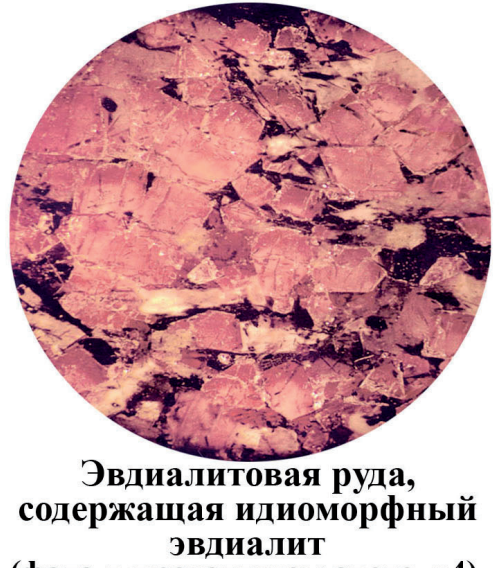

(фото в проходящем свете, $x 4$ )

Рис. 1. Эволюция форм кристаллизации эвдиалита в процессе дифференциации высокощелочной магмы Ловозёрского месторождения.

Fig. 1. Evolution of the forms of eudialite crystallization in the process of differentiation of high-alkalic magma of the Lovozero massif.

Вверх по разрезу (на глубинах порядка 400 м) - в самых нижних зонах третьей интрузивной фазы, эвдиалит становится ранним минералом, образует хорошо оформленные, идиоморфные кристаллы (рис. 1). Формы выделения эвдиалита по идиоморфизму не отличаются от нефелина, полевого шпата, амфибола и эгирина, что указывает на их одновременную кристаллизацию на раннемагматической стадии. Таким образом, петрографические исследования показали, что смена форм выделения главного минерала концентратора циркония - эвдиалита определяется временем кристаллизации этого минерала. Как было показано нами (Kogarko et al., 2002) и другими авторами (Parsons, 1987) формирование многих расслоенных интрузий происходит снизу вверх в результате оседание минералов в процессе кристаллизации и конвективного перемешивания. Однако в некоторых случаях часть кристаллизующихся минеральных фаз всплывает в магматической камере.

Примером подобного процесса являются месторождения апатита Хибинского массива. Очень мелкие кристаллы апатита - в процессе активной конвекции не оседают, а накапливаются в жидкости и по мере остывания интрузии и заполнения магматической камеры кристаллическим осадком апатит вместе с жидкостью поднимается вверх, значительно концентрируется и формируется апатитовое месторождение. Интерстициальный характер эвдиалита во всем разрезе дифференцированного комплекса Ловозерской интрузии свидетельствует о том, что исходная магма не была насыщена в отношении эвдиалита. В целом на основании соотношений объемов дифференцированного и эвдиалитового комплексов, можно заключить, что только после кристаллизации около 85 \% всей 
интрузии, состав остаточного расплава становился насыщенным в отношении эвдиалита и этот минерал становится ликвидусной минеральной фазой. Как ликвидусный минерал эвдиалит выделялся на ранних этапах одновременно с главными породообразующими минералами - нефелином, эгирином, амфиболом и калиевым полевым шпатом.

Наши экспериментальные данные фазовых равновесий в системе эвдиалит-нефелин (Когарко и др., 1988) показали, что концентрация $\mathrm{ZrO}_{2}$ в расплаве, насыщенном в отношении эвдиалита, составляет 1.5 \%. По данным Герасимовского и др. (Герасимовский и др., 1966), среднее содержание $\mathrm{ZrO}_{2}$ в породах дифференцированного комплекса составляет 0.29 \%. Учитывая эту величину и концентрацию насыщения щелочного расплава в отношении эвдиалита $-1.5 \% \mathrm{ZrO}_{2}$, получаем очень близкую величину массы закристаллизовавшегося магматического осадка - 81 \% выделившегося перед насыщением расплава эвдиалитом.

Необходимо учитывать, что в процессе дифференциации щелочной магмы кристаллический осадок захватывал несколько процентов расплава, кроме того, цирконий активно концентрировался во фракционирующих пироксенах, содержание $\mathrm{ZrO}_{2}$ в которых достигает иногда первых процентов. Вследствие этих причин количество кристаллического осадка в остаточном расплаве должно возрасти на несколько процентов для достижения насыщенности в отношении эвдиалита.

Интересно отметить, что смена форм выделения эвдиалита совпадает с внедрением новой порции щелочного расплава в малоглубинную магматическую камеру. Приповерхностный характер эвдиалитовых луявритов подтверждается широким развитием порфировидных луявритов. Мы полагаем, что формирование эвдиалитового комплекса происходило при очень невысоких давлениях, что способствовало расширению поля кристаллизации эвдиалита и формированию эвдиалитовых руд - главного сырья на тяжелые редкие земли, цирконий и гафний. На основании приведенных фактов можно заключить, что смена форм выделения эвдиалита (и времени его кристаллизации) представляет собой новый геохимический критерий рудоносности щелочных магм на редкоэлементное сырье (цирконий, гафний, тяжелые редкие земли). Эвдиалит, в отличие от лопарита и апатита, заметно обогащен тяжелыми редкими землями (рис. 2). Крупный объем руд эвдиалитового комплекса и обогащенность тяжелыми редкими землями свидетельствует об их высокой экономической ценности.

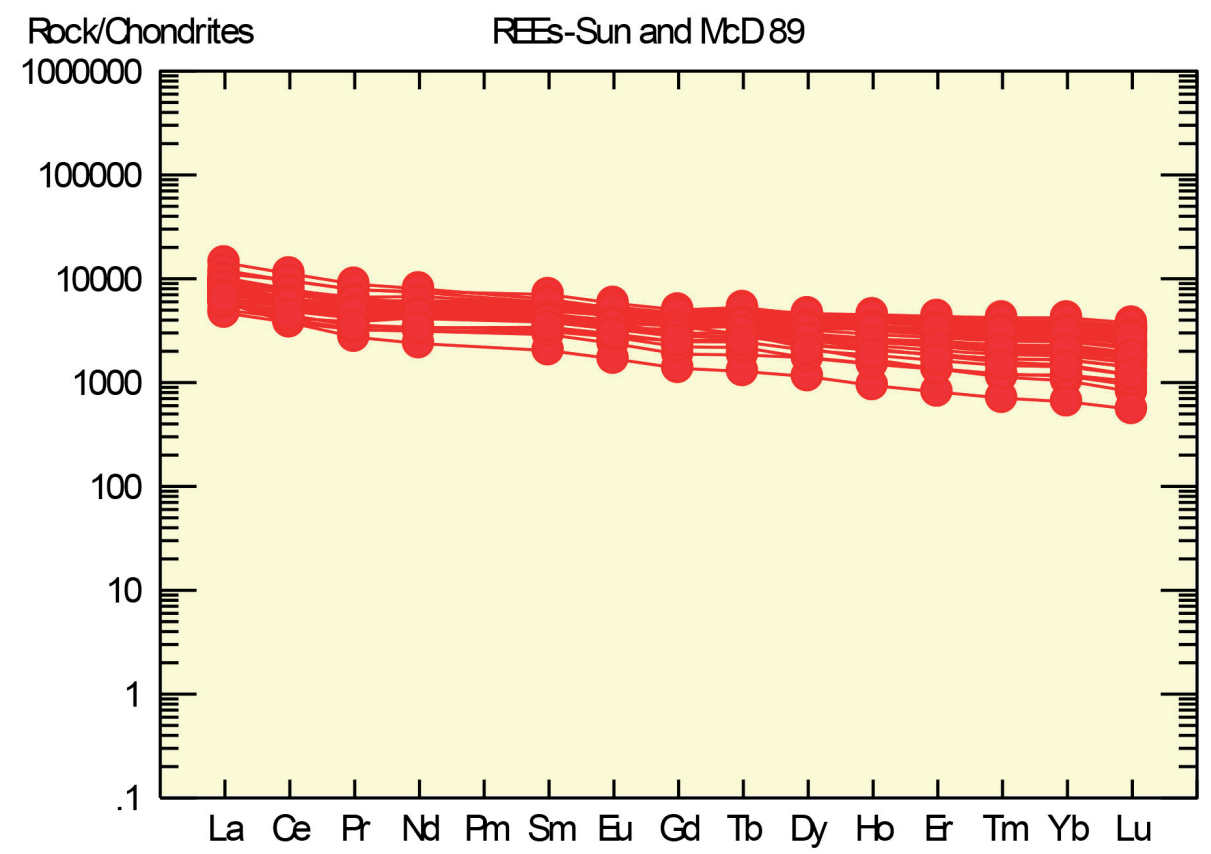

Рис. 2. Распределение REE в эвдиалитах рудоносного эвдиалитового комплекса.

Fig. 2. REE distribution in eudialites of the ore-bearing eudialite complex. 
Из полученных данных следует, что рудоносными зонами гигантской Ловозерской интрузии могут быть только те, которые содержат идиоморфный (кумулятивный) эвдиалит. Дифференцированный комплекс Ловозерской интрузии (глубина около 2300 м) не перспективен на этот тип редкометального сырья.

Таким образом, необходимым условием появления магматических редкометальных месторождений кумулятивного типа является ранняя котектическая насыщенность расплава в отношении рудного минерала. В этом случае отмечается идиоморфизм рудных минералов. Если концентрация рудного компонента значительно ниже котектической, то явления конвективно-гравитационной дифференциации и сегрегации минеральных фаз затруднены, что приводит к рассеиванию рудных компонентов в виде ксеноморфных выделений акцессорных минералов. Кристаллизация рудного минерала в этих случаях будет осуществляться на поздних стадиях формирования пород в малом объеме интерстициального расплава.

Принцип ранней котектической насыщенности магмы в отношении рудного минерала как необходимое условие возникновения магматических руд кумулятивного типа может быть распространен на другие магматические комплексы. В качестве примера можно привести эвдиалитовое месторождение интрузии нефелиновых сиенитов Гренландии - комплекс Илимауссак в породах которого эвдиалит представлен ранними идиоморфными выделениями - то есть исходная магма была насыщена эвдиалитом на самых ранних стадиях. В массиве агпаитовых нефелиновых сиенитов Пилансберг (Южная Африка) эвдиалит выделялся на более поздних стадиях и в этом массиве эвдиалитовые руды отсутствуют. Исходный щелочной расплав Хибинского массива (Кольский полуостров) не был насыщен на ранних этапах в отношении эвдиалита и, несмотря на довольно высокие содержания $\mathrm{ZrO}_{2}$ эвдиалитовые руды отсутствуют во всех интрузивных комплексах Хибинского массива.

Работа выполнена в рамках темы по государственному заданию № 0137-2019-0014.

\section{Литература}

1. Герасимовский В.И., Волков В.П., Когарко Л.Н., Поляков А.И., Саприкина Т.В., Балашов Ю.А. Геохимия Ловозерского щелочного массива. М. Изд-во: Наука. 1966. 392 с.

2. Когарко Л.Н., Лазуткина Л.Н., Кригман Л.Д. Условия концентрирования циркония в магматических процессах. М. Изд-во: Наука. 1988. 120 с.

3. Kogarko L.N., Williams C.T., Wooley A.R. Chemical Evolution and Petrogenetic Implications of Loparite in the Layered, Agpaitic Lovozero Complex, Kola Peninsula, Russia // Mineral. and Petrol. 2002. V. 74. P. 1-24.

4. Kramm U., Kogarko L. Nd and Sr Isotope Signatures of the Khibina and Lovozero Agpaitic Centers, Kola Alkaline Province, Russia // Lithos. 1994. V. 32. P. 225-242.

5. Parsons I. Origin of Igneous Layering. Dordrecht: Reidel. 1987. 561 p. 